\title{
9. Mobile phone registration in \\ Papua New Guinea \\ Will the benefits outweigh the drawbacks?
}

Commentary: The government of Papua New Guinea (PNG) has introduced a requirement for mobile phone registration. This commentary is a comprehensive analysis of the registration regulation, the process and key challenges. The article is based on close observation of developments over several years, including attendance at court cases on the issue. The commentary includes a description of the regulation, definitions of relevant terminology, a timeline of events, reflections on personal experiences, comparison to other countries, and discussion of related issues. In weighing costs against benefits, the author aims to determine the value of such a regulation. A key concern is the risk of poor and disadvantaged people being excluded from mobile phone ownership. While many countries in Africa and elsewhere have introduced similar requirements for registration with the stated objective of improving security, there is little evidence available that this measure does in fact reduce crime. Additionally, in Papua New Guinea, most people do not have any form of written identification documentation, which makes the process of mobile phone registration challenging.

Keywords: cell phones, communication, Melanesia, mobile phones, Pacific studies, Papua New Guinea, registration, security, SIM, technology, transparency

\section{AMANDA H. A. WATSON \\ Australian National University, Canberra}

\section{Introduction}

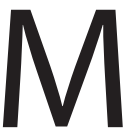

OBILE phone registration is legally required in Papua New Guinea (PNG), under the SIM Card Registration Regulation 2016. ${ }^{1}$ National Gazette No. G228 was signed by the Governor-General in April 2016. All mobile phone SIM cards must be registered with a service provider. A SIM is a Subscriber Identity Module linked to a user's phone number and usually looks like a small computer chip. 
If consumers do not register in time, either their SIM card will be deactivated or the mobile network operator will receive a fine from the regulator (National Information and Communications Technology Authority of Papua New Guinea, or NICTA) for continuing to operate unregistered SIM cards. Registration involves a user providing to the mobile phone company their name, proof of identity and other details. In Papua New Guinea, mobile phone users need to register in person and have their photograph taken.

Proof of identity issues are a major concern, as the majority of people in PNG live in rural areas and do not have written identification such as a drivers' licence or passport. To address this challenge, the regulation allows for use of a letter from a reputable person such as a priest as a means of identification. The global peak body for mobile phone companies has suggested that the 'effectiveness of SIM registration solutions also depends on the availability and pervasiveness of national identity schemes' (GSMA, 2016, p. 4). In PNG, a scheme known as the National Identification (NID) project has been slow to become established and has only reached a fraction of the country's population.

There are 2.8 million active mobile phone SIM cards in use in PNG (Highet et al., 2019, p. 24; Watson \& Park, 2019), operated by 2.5 million unique users (Highet et al., 2019, p. 18). The difference between these figures is because some people use more than one mobile phone number. For example, I have three SIM cards in PNG: a bmobile number, a work Digicel and a personal Digicel. The bulk of the mobile phones in use in PNG are with Digicel, while the recently merged bmobile/Telikom has a small proportion (Highet et al., 2019, p. 19).

\section{Timeline}

The SIM card registration deadline in PNG was initially 23 January 2018. Digicel ran promotions stating that the deadline was 31 December 2017. During December, there were large crowds of people trying to register their SIM cards at stores and makeshift registration stands.

On 23 January 2018, Sam Basil, then Communications Minister, decided to extend the deadline to 30 April 2018. This was because more than one million mobile phones were not yet registered. The PNG Council of Churches then approached NICTA and offered to help with the registration process. The two organisations held coordination workshops in all four regions of the country. Priests in rural areas could only offer residents partial registration though because of the requirement for a photograph to be taken.

On April 30, Madang MP Bryan Kramer, now Papua New Guinea's Police Minister, was granted an interim injunction by the National Court to stop the deactivation of unregistered mobile phones that evening. The stay order constrained NICTA from deactivating SIM cards and allowed 14 days for the parties to prepare for a case to be heard on 15 May 2018. 
On May 15, Kramer asked the court for a further extension, as he was not prepared for the hearing. During a two-hour-long recess, the judge considered the arguments of Kramer and the regulator before he decided not to grant the extension. Kramer then withdrew the matter. Lawyers for the regulator agreed, with each party to bear their own costs. This meant that there was no longer an injunction preventing NICTA from enforcing deactivation of unregistered mobile phone SIM cards.

On 17 May 2018, then Communications Minister Sam Basil extended the deadline for registration by more than two months, to July 31 2018. A devastating earthquake that had hit several PNG Highlands provinces in February 2018 was one reason why the minister decided to further extend the registration deadline (Wani, 2018). At that time, Digicel had registered more than 1.4 million subscribers (Pokiton, 2018). That left roughly 1.1 million subscribers on that network who were yet to register. Digicel had been offering incentives to customers to register, such as free airtime (mobile phone credit).

In July 2018, then President of Karkar Local Level Government in Madang Province, late Ben Naing, said that a team from Digicel had visited Karkar Island on two occasions to register mobile phone users. The team visited several key locations on the island. Ward councillors and village leaders actively encouraged people to register their SIM cards. Earlier research in Naing's village Orora shortly after mobile network coverage reached the island found that villagers viewed mobile service as potentially life-saving during medical emergencies such as childbirth complications (Watson, 2010; see also Watson, 2011; Watson, 2013). By July 2018, Naing was confident that many people on the island had been able to register their SIM cards, although he feared that those in more remote parts of Madang Province may not have been able to.

A similar story was described by Emil Yambel, president of the Basamuk Sports Association, in July 2018. Yambel said that a Digicel team travelled to Basamuk, with transportation and accommodation provided by the Ramu nickel mine. He said that the mine's employees and some villagers registered their SIM cards. However, he was concerned that people residing in surrounding mountain villages were unlikely to have registered their SIM cards.

The date 31 July 2018 was the final day for registration and there were queues at outlets, including temporary registration stalls. Madang MP Bryan Kramer filed proceedings in court late in July, attempting to secure a stay order to prevent deactivation of SIM cards, but this was denied. On 1 August 2018, unregistered SIM cards were deactivated in the capital city Port Moresby and other major urban centres. Customers who woke up to find that their mobile phones were not working queued at outlets to register and thus reactivate their SIM cards.

The regulator NICTA decided to divide the country into three kinds of geographies, which would be handled differently. Unregistered SIM cards in 
urban areas (cities and provincial capitals) ${ }^{2}$ were deactivated on August 1 and users in those places had 30 days to re-claim their phone numbers. Mobile phone users in district towns had until 31 December 2018 to register their SIM cards. Consumers in rural areas had until 30 April 2019. The regulator's intention was to allow people in district towns, rural and remote areas more time to register.

A new date of 1 January 2019 was set as the cut-off date for district towns, including Arawa and Buin in the Autonomous Region of Bougainville, Chuave and Kerowagi in Chimbu Province, Bogia and Gusap in Madang Province, Malalaua in Gulf Province, Namatanai in New Ireland Province, and similarly sized district centres in most other provinces.

There was no evidence of deactivations in district towns in January 2019. NICTA intended to meet with the telecommunication companies during that month. However, the meeting and deactivations did not go ahead because the Ombudsman Commission filed a Supreme Court reference questioning the constitutionality of SIM card registration. Throughout 2019, there were nine mentions of the reference in the Supreme Court, with NICTA and the state establishing themselves as respondents.

The reference was heard by a full bench of the Supreme Court on 18 December 2019, from $1.30 \mathrm{pm}$ until $3 \mathrm{pm}$. The five judges sitting were justices Salika, Kandakasi, Cannings, David and Hartshorn. They did not reach a decision as such. Instead, they declined to give an opinion regarding questions asked of the court by the Ombudsman Commission.

The court proceeding was Supreme Court Reference 1/2019, which was instigated by the Ombudsman Commission as a special reference pursuant to section 19 of the Constitution. In essence, what this meant was that the Ombudsman Commission questioned the constitutionality of mandatory SIM card registration. Deactivation of unregistered SIM cards was on hold for most of 2019 while this matter was awaiting resolution.

The SIM card regulation stemmed from the NICTA Act, as the enabling or parent act. The Commission tried to argue that the regulation restricts certain freedoms enshrined in the constitution and therefore such a regulation should have to go through parliament. The Commission's first question of the court did not specify any act or regulation, but instead asked the court to consider whether or not a regulation which impacts upon freedoms should be passed by a majority in Parliament even though it is linked to an act which has been through the same process. Two further questions were submitted by the Commission to the court, but these were not discussed in detail because judges interrupted the Commission's presentation to ask about the express rights being infringed.

Lawyer Charles Kaki from Kawat Lawyers was representing NICTA. He said that the first question was too general and stated that the second and third questions stemmed from the first question. He said that the submission was 
incompetent and suggested that perhaps the court could direct the Ombudsman Commission to re-frame the questions. Lawyer Tauvasa Tanuvasa Chou-Lee, the Solicitor General of Papua New Guinea, suggested that the court should decline to answer the questions raised by the Ombudsman Commission. The judges conferred among themselves and then announced that they had decided to decline to give an opinion on the three questions put to them. They said that the questions had no immediate relevance to circumstances in PNG.

Following the court case, the new Communications Minister, Timothy Masiu, seemed to be concerned about the ability for mobile phone users in rural areas to register their SIM cards. He then announced that 31 March 2020 was the new deadline. Late in March, Masiu granted a four-month-long extension of the deadline, to 31 July 2020, due to the global Covid-19 pandemic (Gware, 2020; Moi, 2020).

\section{Personal experience}

In December 2017, I was reminded about the need to register my SIM cards through promotional messages, such as advertisements on radio and television produced by mobile phone companies and NICTA. I registered a bmobile SIM card easily and quickly at a bmobile retail outlet in Port Moresby. A staff member completed my details using a tablet. Information required included my name, address, sex, and date of birth. I was given the impression that it was not possible to leave any fields blank. I used my PNG driver's licence as proof of identity.

I also needed to register a Digicel SIM card, but there were always queues at Digicel outlets and the registration process itself also seemed lengthier. I had to complete a paper form and then a staff member entered all my details onto a tablet while I waited. My photograph was taken and a confirmation code was sent to my mobile phone. I needed to provide this code in order for the registration process to be complete. I wanted to leave some fields blank, but was told by the staff member that if I did so my registration would not be accepted as valid. There were some questions about Digicel services, such as mobile money, which had been included. Again, I used my PNG drivers' licence as proof of identity. I did not need to register my third SIM card because it was managed by my employer.

For me, the registration process was time-consuming. It raised questions about privacy and data security because personal details such as my date of birth were entered into databases belonging to commercial entities. For an illiterate or semi-literate PNG citizen with no driver's licence or other form of written identification, the process may be challenging and confronting.

\section{Comparisons to other countries}

In various countries, SIM card registration has been introduced. Governments 
often adopt such a policy in order 'to help mitigate security concerns and to address criminal and anti-social behaviour' (GSMA, 2016, p. 2; see also Mamabolo, 2017). In Papua New Guinea, similar motivations for the policy have been expressed (Loop Technology, 2018). A concern though is that 'to date, there has been no empirical evidence that mandatory SIM registration directly leads to a reduction in crime' (GSMA, 2016, p. 2; see also Mamabolo 2017). Indeed, in Mexico, the theft of handsets increased after a similar policy was introduced, likely because 'criminals stole handsets to avoid the risk of being traced by security authorities' (GSMA, 2016, p. 17). Mexico subsequently abandoned their SIM registration policy and later introduced a scheme for registering handsets. Several countries in Latin America have opted for handset registration in order to address handset theft (GSMA, 2016, pp. 22-23).

Papua New Guinea's neighbour Indonesia instigated a similar exercise of SIM card registration. The deadline was 28 February 2018, at which time more than 100 million SIM cards were partially blocked, before a further deadline of 30 April 2018. In that case, registration could be done online, through text messaging, at a call centre, or in person. It was relatively easy for Indonesian consumers to register their mobile phones as each person has both a family identification number and a personal identification number.

In Uganda, a similar process has been conducted and mobile operators have been able to confirm a user's identity by interfacing with a national identification database (Mpairwe, 2018). In addition to Uganda, numerous countries in Africa have introduced compulsory SIM card registration (Mamabolo, 2017). According to Gillwald, this process has been locking poor people out of mobile phone ownership (quoted in Mamabolo, 2017). Gillwald has argued that 'despite little evidence that mandatory SIM registration contributes to safeguarding our digital security or physical safety, it has become a universal regulatory standard in Africa to facilitate the monitoring and interception of communications' (n.d., n.p.).

\section{Related issues}

For all the effort being made by consumers and telecommunication companies, I wonder about the extent to which the process will lead to tangible benefits for the country. Certainly, the exercise is costing the operators money, as has also been observed elsewhere (Song, 2016). In some countries, for instance Nigeria, the regulatory body shouldered initial registration costs (GSMA, 2016, p. 23).

There is a risk that vulnerable or socially marginalised people are excluded from the opportunity to own and use mobile phones. The staged approach to deactivations has given rural and remote users more time to register, but for many of these people the registration of SIM cards is challenging. In many cases, people need to travel to a town to register their SIM cards, thus incurring transportation costs. While registration is supposed to be free-of-charge, sources 
suggest that sub-contractors in some provinces have been charging consumers money to register.

When similar initiatives have been introduced in other countries, deadlines have been extended, but nonetheless SIM cards have been deactivated after the final deadline. Deactivation would likely result in decreased revenue for operators and for the government through taxes. But perhaps more importantly, this policy could lead to an absence of two-way communication in disadvantaged communities in PNG. If the few active mobile phones in certain remote villages are cut off, this could have negative implications regarding time-critical emergency communication, such as for childbirth complications (Watson et al., 2015) and natural disasters (Watson, 2012). Citizens in such places may need to overcome this hurdle in order to ensure that they are not left even further behind.

\section{Conclusion}

Countries usually state that security is the impetus for the introduction of mandatory SIM card registration, although there is little evidence to show that it addresses crime (see 'Comparisons to other countries' section above). Numerous countries have introduced such a process, with seemingly better success where there is an existing national identification database (see GSMA, 2016, p. 4).

There has also been a monetary cost incurred by users when registering SIM cards, including transportation costs (see 'Related issues' section above). There have been concerns expressed by some users about the security of personal data in the databases held by telecommunication companies. Comments on my analysis have referred to religious and spiritual beliefs held by some groups within PNG, which could cause reluctance to share personal data. Customer anxiety could perhaps be eased through increased transparency about data use.

Will the benefits outweigh the drawbacks? Compulsory registration may mean that certain citizens are able to ask the police to pursue criminals who have been harassing them through their mobile phones. My concern though is that the process may lead to the deactivation of many mobile phones because enforcement of SIM card registration on the African continent has had negative effects, especially regarding poor people's access to mobile phones (Mamabolo, 2017).

\footnotetext{
Notes

${ }^{1}$ This article is the only comprehensive analysis of mandatory SIM card registration in Papua New Guinea. Earlier work appeared in Devpolicy blog posts.

${ }^{2}$ Apart from those provincial capitals impacted on by the February 2018 earthquake: Wabag (Enga Province), Tari (Hela Province) and Mendi (Southern Highlands). They were given until 31 December 2018.
} 


\section{References}

Gillwald, A. (n.d.). African nations use SIM card question to mandate control. Research ICT Africa. Retrieved on 20 April 2020, from https://www.researchictafrica.net/publications/Other_publications/2015_Gillwald_Terror $\% 20$ fear $\% 20$ enables $\% 20$ veil $\% 20$ of $\% 20$ surveillance.pdf

GSMA (2016). Mandatory registration of prepaid SIM cards. GSMA. Retrieved on 20 April 2020, from https:/www.gsma.com/publicpolicy/wp-content/uploads/2016/04/ GSMA2016_Report_MandatoryRegistrationOfPrepaidSIMCards.pdf

Gware, C. (2020, March 30). SIM deactivation deadline pushed back. Loop PNG. Retrieved on 20 April 2020, from http://www.looppng.com/tech/sim-deactivationdeadline-pushed-back-91062

Highet, C., Nique, M., Watson, A. H. A., \& Wilson, A. (2019). Digital transformation: The role of mobile technology in Papua New Guinea. London, UK: GSMA.

Loop Technology (2018, January 8). Register your SIM for safety, security: Basil. Loop $P N G$. Retrieved on 20 April 2020, from http://www.looppng.com/tech/register-yoursim-safety-security-basil-71973

Mamabolo, M. (2017, April 4). Analyst says SIM card registration in Uganda is illadvised. ITWeb. Retrieved on 20 April 2020, from https:/itweb.africa/content/ P3gQ2MGxEdGqnRD1

Moi, C. (2020, March 31). Nicta moves sim card deadline. The National. Retrieved on 20 April 2020, from https://www.thenational.com.pg/nicta-moves-sim-card-deadline/

Mpairwe, H. (2018, April 18). UCC resumes SIM card registration and replacement exercise with tough conditions on multiple subscribers. TechJaja. Retrieved on 20 April 2020, from https://techjaja.com/ucc-resumes-sim-card-registration-and-replacementexercise-with-tough-conditions-on-multiple-subscribers/

Pokiton, S. (2018, May 16). SIM registration extended. Loop PNG. Retrieved on 20 April 2020, from http://www.looppng.com/tech/sim-registration-extended-76603

Song, S. (2016, January 6). What if everyone had free $2 \mathrm{G}$ mobile internet access? ICTWorks. Retrieved on 20 April 2020, from https://www.ictworks.org/what-if-everyonehad-free-2g-mobile-internet-access/\#.Xp0kb67ivIW

Wani, D. (2018, May 17). More time to register. The National. Retrieved on 20 April 2020, from https://www.thenational.com.pg/more-time-to-register/

Watson, A. H. A., (2010). 'We would have saved her life': Mobile telephony in an island village in Papua New Guinea. ejournalist, 10(2), 106-127.

Watson, A. H. A., (2011). Early experience of mobile telephony: A comparison of two villages in Papua New Guinea. Media Asia, 38(3), 170-180.

Watson, A. H. A., (2012). Tsunami alert: The mobile phone difference. Australian Journal of Emergency Management, 27(4), 46-50.

Watson, A. (2013). Mobile phones and media use in Madang province of Papua New Guinea. Pacific Journalism Review : Te Koakoa, 19(2), 156-175. https://doi. org/10.24135/pjr.v19i2.223

Watson, A. H. A., \& Park, K. R. (2019, August 13). The digital divide between and within countries. Devpolicy. Retrieved on 20 April 2020, from https://devpolicy.org/ the-digital-divide-between-and-within-countries-20190813/

Watson, A. H. A., Sabumei, G., Mola, G., \& Iedema, R. (2015). Maternal health phone line: Saving women in Papua New Guinea. Journal of Personalized Medicine, 5 , 120-139. 
DrAmanda HA Watson is a research fellow with the Department of Pacific Affairs at Australian National University. Dr Watson's research focuses on mobile phone use in Papua New Guinea.

amanda.watson@anu.edu.au

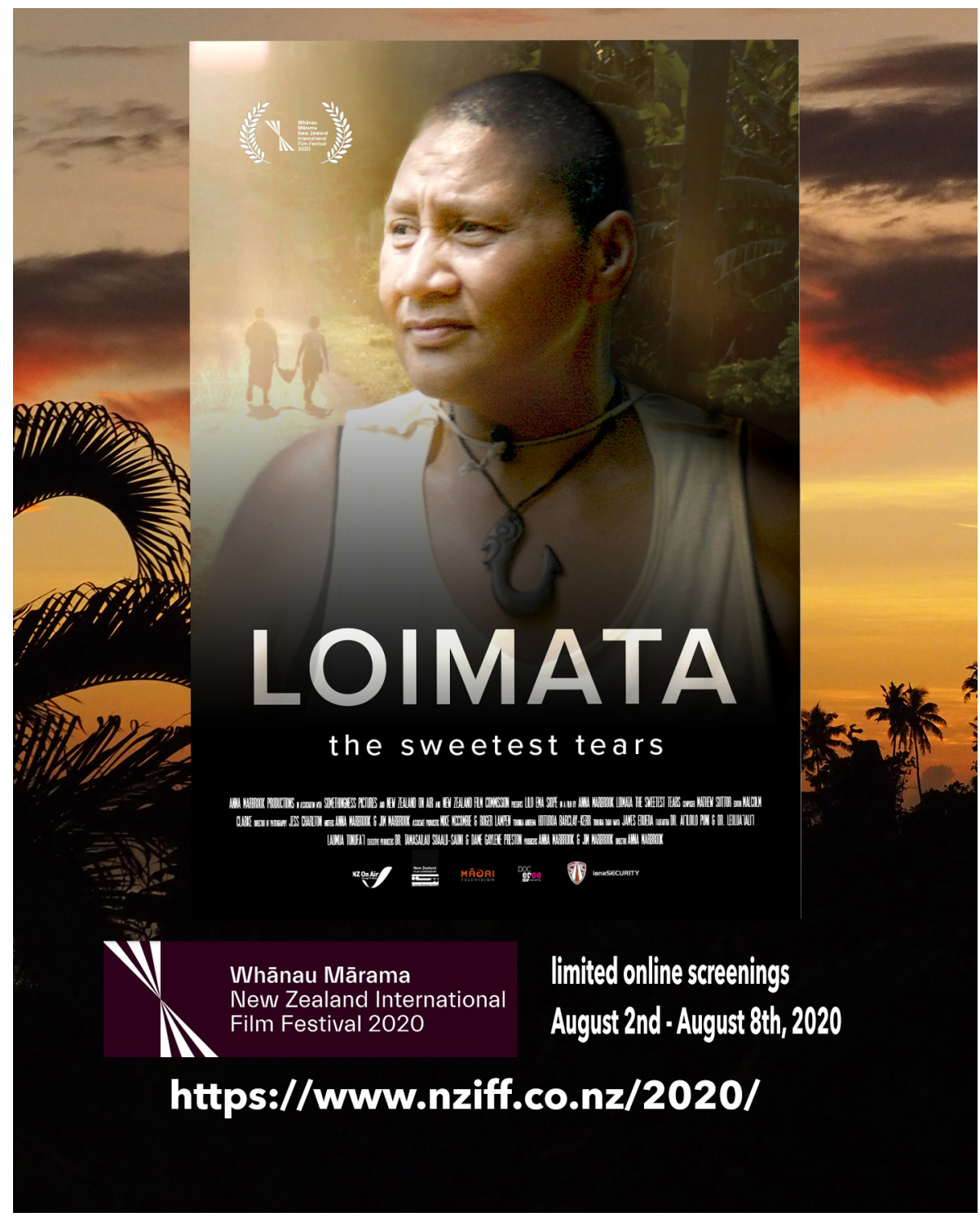

